\title{
AC 2008-2357: THE STATE OF ENGINEERING PROGRAM ACCREDITATION AND QUALITY ASSURANCE IN CANADA
}

\section{Deborah Wolfe, Engineers Canada}

Deborah Wolfe, P.Eng. is Director, Education, Outreach and Research with Engineers Canada, the federation of the engineering regulatory bodies in Canada. She is responsible for the operation of the accreditation system for undergraduate engineering programs in Canada as well as Engineers Canada's research program, outreach activities, and foreign credential evaluation program. Ms. Wolfe is a licensed professional engineer in the province of Ontario, Canada.

\section{Phil Alexander, University of Windsor}

Phil Alexander, P. Eng., is Associate Professor Emeritus in Electrical and Computer Engineering, at the University of Windsor where he has served as Department Head, and as Associate Dean (Academic) of the Faculty of Engineering. He has served for over five years on the CEAB, and is currently a member of its Policy and Procedures Committee. Prof. Alexander is a registered professional engineer in the Province of Ontario, Canada. 


\title{
The State of Engineering Program Accreditation and Quality Assurance in Canada
}

\begin{abstract}
The accreditation system for engineering education as it is implemented in Canada is described in terms of a brief history, and an explanation of the approach which it incorporates. It includes a quality assurance component, but also provides for the preparation of graduates for proceeding to professional licensure. The internationally focused activities conducted to ensure Canadian awareness of the relationship of its system to those which are in place elsewhere in the world and which facilitate obtaining mutual recognition between its and other national accreditation systems is explained. The nature of the active Canadian program of assistance to countries which are on a path to developing their own accreditation systems is presented. Current activities associated with its shift into the more outcomes-based assessment approaches which are increasingly being used in the world, and the future challenges presented by this trend and by the emergence of potential new engineering disciplines close the paper.
\end{abstract}

\section{Introduction to the Canadian Engineering Accreditation Board}

The Canadian Council of Professional Engineers (CCPE, hereinafter referenced as Engineers Canada, its business name) is the federation of provincial and territorial regulatory bodies (constituent members or CMs) which license professional engineers, each within its jurisdiction. It coordinates certain aspects of the profession across Canada. The Canadian Engineering Accreditation Board (CEAB), a standing committee of Engineers Canada, is responsible for the accreditation of Canadian engineering education programs.

The CEAB has two goals:

- that engineering programs offered by Canadian universities will meet or exceed minimum educational standards acceptable for professional engineering licensure in Canada; and

- that the quality and relevance of engineering education will continuously improve.

The CEAB strives to meet these goals by continuously reviewing and updating the policies and procedures for evaluating university engineering programs.

In addition to advising Engineers Canada on all matters related to engineering education, the $\mathrm{CEAB}$ works closely with Canadian universities to ensure that accredited engineering programs are able to impart to their graduates the skills and knowledge needed to become productive members of the profession. It also offers advice to universities developing new engineering programs, to help them ensure that those programs ultimately meet the criteria for accreditation specified by Engineers Canada. As part of this process, Engineers Canada produces an annual report outlining the CEAB's criteria and procedures ${ }^{1}$. The report lists the Canadian undergraduate engineering programs that are currently, or have ever been, accredited by the $\mathrm{CEAB}$. It also describes the work and composition of the teams of volunteers who conduct program evaluation visits to Canadian universities on the CEAB's behalf. Several subcommittees, including the Executive Committee, Policies and Procedures Committee, and 
Nominating Committee, assist the CEAB in its work. The CEAB is currently composed of fifteen professional engineers drawn from the private, public and academic sectors. The members are volunteers and represent different parts of the country as well as a wide range of engineering disciplines. The CEAB serves both English and French language institutions.

\section{A Historical Perspective on Engineers Canada and the CEAB}

Established in 1936, as CCPE, Engineers Canada is the national organization of the 12 provincial and territorial constituent members that regulate the practice of engineering in Canada and license the country's more than 160,000 professional engineers. Engineers Canada serves its constituent members by ensuring on a national basis, that the highest standards of engineering education, professional qualifications and ethical conduct are in place.

In addition to being the voice of its constituent members in national and international affairs, Engineers Canada establishes national policies, positions and guidelines on behalf of the engineering profession. It also promotes greater understanding of the nature, role and contribution of engineering to society, and undertakes federal government relations and national media relations on behalf of, and in consultation with, its constituent members.

The Engineers Canada's policy setting and governing body is the Engineers Canada Board of Directors on which there is representation from each of Canada's 12 licensing bodies. Engineers Canada also has several operational Boards and Committees that undertake a wide range of activities and initiatives to implement the policies established by the Engineers Canada Board of Directors. They include:

- Canadian Engineering Accreditation Board

- Canadian Engineering Qualifications Board

- International Committee

In 1965, the then CCPE established the Canadian Accreditation Board (CAB), now known as the Canadian Engineering Accreditation Board, to accredit Canadian undergraduate engineering programs that meet or exceed the minimum educational criteria. Experience requirements as prescribed by the provincial/territorial $\mathrm{CM}$ in the region of the institution must also be met for a candidate to become licensed in that Canadian jurisdiction.

The CEAB is also responsible for ascertaining the degree of equivalence of accreditation systems in other countries and for monitoring the activities of those bodies with which mutual recognition agreements have been signed.

\section{Accreditation and Substantial Equivalency Evaluations}

An accreditation visit is undertaken at the invitation of a particular institution and with the concurrence of the constituent member having jurisdiction. A team of senior engineers is assembled under the direction of a current or recent CEAB member. A detailed questionnaire is completed by the institution and sent to the team prior to the visit. During the visit, the team examines the academic and professional quality of faculty and support staff, adequacy of laboratories, libraries, equipment and computer facilities, and the quality of the students' work. 
A qualitative and quantitative analysis of the curriculum content is performed to ensure that it meets the minimum criteria. Finally, the team reports its findings to the CEAB which then makes an accreditation decision. It may grant (or extend) accreditation of a program for a period of up to six years or it may deny accreditation altogether.

Preparation for an accreditation visit centres on the completion of the questionnaire. The questionnaire serves as a means for collecting data on the institution and its engineering program(s) and gives the institution an opportunity to review and articulate its educational objectives and processes.

The visiting team considers the information provided by the institution and that which it has gathered while on site. The team reports the pertinent information distilled so that the CEAB, in its subsequent deliberations, may make an informed accreditation decision.

In Canada, 40 educational institutions offer accredited undergraduate engineering programs leading to an engineering degree at the bachelor level. There are currently more than 230 accredited engineering programs, in a wide range of engineering disciplines. In addition to the well-known disciplines such as civil, electrical, mechanical and chemical engineering, aspiring engineers can enter accredited programs in bioresource, computer, environmental, materials, mining and software engineering, among others.

Engineers Canada, through its International Committee (IC), strives to achieve recognition by the international community of Canadian standards of excellence in engineering education and practice. Where appropriate, Engineers Canada will enter into agreements with other nonCanadian organizations concerning mutual recognition of accreditation systems or professional engineering qualifications. The CEAB assists in this mission by ascertaining the equivalency and acceptability of accreditation systems in other countries relative to the Canadian system, and by evaluating, upon request, engineering education programs in other countries.

These evaluations follow the CEAB's policies and procedures, but may only lead to a decision of "substantial equivalency" for such programs in foreign institutions. The term "substantial equivalency" means "comparable in program content and educational experience" and it implies reasonable confidence that the graduates possess the academic competencies needed to begin professional practice at the entry level. The CEAB recommends that the Canadian licensing bodies treat graduates of programs evaluated as substantially equivalent as if they were graduates of CEAB-accredited programs for the period that substantial equivalence is in effect. Since $\mathrm{CEAB}$ accreditation is designed to provide graduates with an education satisfying the academic requirements for licensure within Canada, the CEAB uses the term 'accreditation' only within Canada.

Through the CEAB's activities, the Canadian criteria and procedures for accrediting undergraduate engineering programs are now recognized around the world. As a result, there are ten programs at four institutions in three countries that have been deemed substantially equivalent to a CEAB program and several other institutions have expressed an interest in having their engineering programs evaluated by the CEAB. 


\section{Accreditation and Engineers Canada's International Activities}

Engineers Canada, through the CEAB, has signed mutual recognition agreements with the accreditation bodies of several other countries. Three agreements currently in force recognize that the systems of the CEAB and the other party for accreditation of programs leading to a degree in engineering are substantially equivalent and that the accredited programs of both parties satisfy the academic requirements for entry to the practice of engineering at a professional level.

The first of these agreements was signed in 1980 by the CEAB and the Engineering Accreditation Commission (EAC) of the Accreditation Board for Engineering and Technology $(\mathrm{ABET})^{2}$ in the United States of America. This agreement was updated and ratified by both parties during the course of 1996 and 1997. The agreement is valid for graduates of all programs accredited by the EAC.

The second of these agreements, entitled "Recognition of Equivalency of Engineering Education Courses/Programs Leading to the Accredited Engineering Degree", was signed by representatives of engineering organizations from six countries. Following a series of verification activities by the CEAB, this agreement was approved and ratified by Engineers Canada and is valid for graduates from 1989 onward. The signatory countries to this agreement were: Canada, Australia, Ireland, New Zealand, the United Kingdom and the United States of America. In 1997, this agreement (now called "The Washington Accord"3) was revised, mostly with respect to rules and procedures, subject to ratification by each of the signatories. Engineers Canada has since ratified the Agreement. Six further countries were subsequently added as signatories to this agreement: Hong Kong (valid for graduates from 1995 onwards), and South Africa (valid for graduates from 1999 onwards), Japan (valid for graduates from 2005 onwards), Singapore (valid for graduates from 2006 onwards), Korea (valid for graduates from 2007 onwards) and Taiwan (Chinese Taipei) (valid for graduates from 2007 onwards).

The Rules and Procedures of the Washington Accord provide a summary of the history of the Accord's development. A more personalized and detailed compendium of events and individuals associated with the development of accreditation in the United States and related world activities may be found in the $75^{\text {th }}$ Anniversary Retrospective of ABET edited by John W. Prados ${ }^{4}$.

A growing benefit of membership in the Washington Accord, beyond the very important result of mobility for graduates, is the collaboration with similar organizations on the development of polices and procedures. Among other issues, work is being done on defining the boundaries of education for engineers, technologists and technicians and managing the changing levels and standards in member countries. Given the developments in engineering education in Europe and around the world, this work is invaluable to the CEAB.

In 1999, Engineers Canada concluded an Agreement with the Commission des Titres d'Ingénieur $(\mathrm{CTI})^{5}$ in France which considers that the accreditation processes used by CTI and the CEAB of Engineers Canada are substantially equivalent. The agreement enables recognition of Canadian engineers who are graduates of CEAB accredited programs as "ingénieurs diplômés" in France. Ingénieurs diplômés who are graduates of programs recognized by CTI are recommended to be 
treated by the Canadian engineering licensing bodies as if they were graduates of CEAB accredited programs - that is, they do not have to pass technical examinations to prove their academic qualifications. The agreement was reviewed, revised and re-signed in 2006. (Please note that not all provincial/territorial regulatory bodies have yet ratified the agreement).

\section{The CEAB Accreditation Criteria}

The CEAB develops the criteria governing the accreditation processes and procedures. The Engineers Canada Board of Directors on behalf of the constituent members approves these criteria. The criteria are both quantitative and qualitative, and place emphasis on curriculum content and the quality of the students, academic staff, support staff and educational facilities. $\mathrm{CEAB}$ also uses these same criteria to conduct substantial equivalency evaluations of engineering programs outside Canada. The criteria have evolved over the years to reflect addressing such issues as technological advances and the growth of the engineering team in the workplace. Over the past decade the CEAB has increased the requirements for complementary studies (soft skills) and moved from a proportional measure of curriculum to an absolute measure. Changes recently implemented in the CEAB criteria include:

- refining the curriculum content requirements for Basic (natural) Science and Mathematics to allow more flexibility,

- including morale and commitment of faculty, support staff and students as a component of the qualitative evaluation, and

- including the requirement for students to be involved in a culminating design experience which includes exposure to the concepts of project management.

Furthermore, as part of its continuous cycle of quality improvement, the CEAB is implementing changes to the criteria, which include:

- enhancing factors related to outcomes-based assessment,

- modifying the options available to universities following a denial of accreditation,

- improving the area of 'Complementary Studies' to better reflect the essential contribution which the associated skills provide to a practitioner,

- refining the expectations for licensure of engineering instructors, and

- refining the 'Advanced Standing, Prior Studies and Exchange Studies Regulations' which is a supplement to the CEAB Accreditation Criteria and Procedures.

The engineering profession expects its members to maintain competence in engineering as well as to have an understanding of the relationship between engineering and society. Thus, accredited engineering programs must contain not only adequate mathematics, science and engineering, but they must also contain adequate complementary studies, some of which deal with central issues, methodologies and thought processes of the humanities and social sciences.

The criteria are intended to:

- ensure that programs develop an individual's ability to use appropriate knowledge and information to convert, utilize and manage resources optimally through effective analysis, interpretation and decision-making while taking appropriate account of environmental considerations. This ability is essential to the design process that characterizes the practice of engineering. 
- provide a broad basis for identifying acceptable engineering programs, which do not have over-specialization in curricula, provide sufficient freedom to accommodate innovative educational development, allow adaptation to different regional factors and permit an appropriate expression of the institution's individual qualities and ideals.

- reflect the need for the engineer to be adaptive, creative, resourceful and responsive to changes in society, technology and career demands.

- ensure that students are made aware of the role and responsibilities of the professional engineer in society and the impact that engineering in all its forms makes on the environmental, economic, social and cultural aspects of society.

- reflect the need for the professional engineer to function as an effective member of a team, able to communicate well, both within the profession and with society at large.

The criteria for curriculum content assure a foundation in mathematics and basic (natural) sciences, a broad preparation in engineering sciences and engineering design and an exposure to non-technical subjects that complement the technical aspects of the curriculum. Judgment is applied to both the qualitative and quantitative criteria requirements in each instance. Outcomes based assessment is being used as a tool within the accreditation system to evaluate the program's goals. The CEAB is currently exploring further use of outcomes based assessment. Another related idea under consideration is switching perspectives from evaluating teaching to evaluating learning.

The CEAB gives sympathetic consideration to departures from some prescriptive criteria parameters in a case in which it is convinced that well-considered innovation in engineering education is in progress. To satisfy accreditation requirements, an engineering program must include at least a minimum of each of the curriculum components specified.

\section{The CEAB and Canadian Engineering Licensing Bodies}

In Canada, the regulation of the engineering profession is a provincial and territorial responsibility. This responsibility has been delegated to engineering's 12 licensing bodies by provincial and territorial statute. Engineers Canada is the national organization of the licensing bodies, but has no regulatory authority over the profession in its own right.

In the Canadian context the purpose of accreditation is to identify to the constituent members of Engineers Canada those engineering programs that meet the criteria for accreditation. Still, in Canada, each of the twelve constituent members has entrenched in its enabling, self-governing legislation a statement of objectives that includes something along the lines of: "...to establish and maintain standards of knowledge and skill among its members ... in order that the public interest may be served and protected..."6.

Within this direct linkage between accreditation and protection of the public interest, there is heightened sensitivity to the responsibility to ensure that educational programs titled "__ engineering" are indeed accreditable as such and that those programs which do not meet the accreditation criteria are excluded from recognition. It is therefore essential that the engineering profession be equally sensitized and alert to new uses of those ubiquitous terms engineer, engineered and engineering, so as to take early steps to prevent confusion in the public 
mind. The accreditation process must be designed to support this activity with criteria that clearly identify those programs that are truly sound bases of the formation of new engineers, yet which are implemented with sufficient flexibility to recognize the legitimacy of emerging, innovative new disciplines.

\section{Current Challenges for the CEAB}

\section{Early Identification:}

The in-place early identification process for emerging innovative engineering disciplines, may need to be coupled with some level of "management" of the emerging process. Identification will continue to involve accreditation boards since these have direct contact with academia on a continual basis. However, the engineering licensing bodies will also need to analyze significant documented lapses in satisfactory practitioner performance in a more intensive fashion and possibly consult with accreditation boards on potential measures to be considered for improvement of accreditation/licensing system processes.

The engineering profession has survived well with its current accreditation criteria-viz. the university degrees with significant instructional input from non-engineers in subject areas such as engineering science, geological engineering, forest engineering, biomedical engineering, etc. But can such fields as genetic engineering be offered following the same model? Is the increase in the non-technical/social content to be accomplished through replacement of some of the technical content or by adding to the existing requirements? It seems certain that criteria cannot escape further modification if we wish to maintain the current high standard, yet embrace legitimate new engineering disciplines affecting the public interest.

\section{Experiential Learning:}

Experiential learning is increasingly popular with employers - co-op terms, internships, stage projects, professional experience terms - all enhance employment opportunities for participating students. Is this an indication that educators (in Canada at least) have been too focused on preparation for post-graduate work or is it a reflection that in a global economy industrial milieu, organizations large and small, can no longer tolerate extended years of internship for new engineering graduates?

Probably not enough is yet known about the pedagogical issues involved in this kind of learning - what do "we" want from it? - who is "we" (industry only, or learned societies or the profession)? - does it enhance Complementary Studies learning? Most importantly, if experiential learning should be brought into accreditation criteria, how will the accreditation boards measure the consistency of the experience and against what specific level or benchmark? - or should accreditation look to modular problem-based learning, and just in time learning, as a preferred model that in some way will serve to initiate the internship earlier than at present, while guaranteeing the consistency of the "teaching"?

Alternatively, should experiential learning be removed from academic/accreditation consideration and given over totally to the licensing bodies to administer as part of the internship process? While this approach might be appropriate from the strict perspective of the issues raised 
above, there are still pedagogical considerations that would best be addressed by academic accreditation teams. The challenge is to find the right approach, given the very strong preference for this kind of learning regularly expressed by the employment marketplace.

\section{Specialization:}

Engineering specialization is an area now under study in Canada by Engineers Canada (and other agencies). Well established in the United States (e.g. California, Washington) and recognized there as an "add-on" to the basic P.E. qualification, it is still early enough in Canada to raise questions as to how (or whether) to distinguish between a specialty and a new discipline. An added consideration is the licensing of eminently but often narrower qualified engineers from offshore for short-term assignments and for immigration. Do these situations involve accreditation issues, or are they adequately addressed ad-hoc by the licensing bodies through their Boards of Examiners?

New disciplines commonly emerge as options that have matured under the more traditional disciplines, - e.g. electrical engineering to computer engineering to software engineering - or as new extensions of a science, e.g. forest engineering, or biomedical engineering. Specializations seem to have emerged driven by perceived market demand or in response to a need for advanced capability perceived by some level of government, perhaps due to a local condition rather than a national one. What are the issues arising from the accreditation of a building engineering degree on the one hand and a "building engineer" specialization required to perform certain certifications under public legislation in a single jurisdiction, on the other? Is the public interest best served if each Board of Examiners has to be involved with all other sister jurisdictions to assess transferees holding the specialization designation? How does the accreditation board respond to the first structural engineering program submitted for accreditation, given that there has never been a stand-alone structural engineering program in Canada and it would likely be far narrower than the norm?

\section{Non-Academic Instruction:}

As part of their engineering design content Canadian universities make strong use of projects solicited from and put forward by private sector organizations, often involving the submitting firms in both advisory and evaluation roles. This seems to acknowledge the need for "real life" projects as a break from the strictly academic, theoretical framework and the involvement of non-academic engineers to provide the "applications" perspective. It also often provides students with valuable experience in presenting their cases outside the classroom environment.

Such experience often provides the only exposure to such things as codes and their requirements, assessments of loadings for which there are no handbooks and the realities of limited budgets and project phasing, that students get. Given the earlier mentioned link between accreditation and the licensing bodies, the question arises as to whether the accreditation criteria should be amended to embed this practice. While Canadian criteria already stipulate that engineering science and engineering design content be taught by "P.Eng's" (licensed engineers), the focus intended has been on the academic faculty. A practice observed in some countries is to require 
that new faculty members have some engineering experience outside the university environment. Should some portion of an accredited program be reserved for presentation by non-academic members of the profession or does this encroach on the universities' freedoms or further still, is it moving some of the internship phase inappropriately back into the academic formation?

\section{Conclusion}

While the foregoing considerations are all raised in the Canadian context, each in its own way also has implications in the global sense, particularly as engineers are increasingly mobile. The challenge for the CEAB will continue to be to facilitate innovation within universities, while remaining fully mindful of the "public interest" obligation of the profession.

\section{Acknowledgements}

The authors would like to acknowledge the work done by J.-Y. Chagnon, ing., and W.G. Paterson, P. Eng., former chairs of the Canadian Engineering Accreditation Board for their ground-work in developing a version of this paper for an earlier time period.

\footnotetext{
${ }^{1}$ http://www.engineerscanada.ca/e/prog_publications_3.cfm , accessed 26 February, 2008.

2 http://www.abet.org/history.shtml, accessed 26 February, 2008.

3 http://www.washingtonaccord.org/Rules-and-Procedures-Aug-2007.pdf, accessed 26 February, 2008.

4 A Proud Legacy of Quality Assurance in the Preparation of Technical Professionals: ABET 75th Anniversary Retrospective, Edited by John W. Prados, Ph.D., P.E. [in publication]

${ }^{5}$ http://www.engineerscanada.ca/e/mob_international.cfm, accessed 26 February, 2008.

6 E.g., for Ontario, http://www.e-laws.gov.on.ca/html/statutes/english/elaws_statutes_90p28_e.htm, accessed 26 February, 2008.
} 